\title{
HOME DIALYSIS DURING COVID-19 OUTBREAK - IT IS WORTH TO CONSIDER
}

10.36740/WLek202010141

\author{
Paweł Żebrowski ${ }^{1}$, Jacek Zawierucha ${ }^{2}$, Wojciech Marcinkowski ${ }^{2}$, Tomasz Prystacki ${ }^{2}$, Inga Chomicka ${ }^{1}$, \\ Jolanta Malyszko ${ }^{1}$ \\ 'NEPHROLOGY, DIALYSIS AND INTERNAL MEDICINE, WARSAW MEDICAL UNIVERSITY, WARSAW, POLAND \\ 2FRESENIUS MEDICAL CARE POLSKA S.A., FMC, POLAND
}

\begin{abstract}
The epidemic with the new SARS-CoV-2 virus poses a serious threat to patients treated with renal replacement therapy. Besides clinical risk factors (such as numerous comorbidities, immune disorders), dialysis patients are additionally exposed to the virus through regular stays for several hours in a dialysis center and ambulance journeys. In such an epidemiological situation, it seems that peritoneal dialysis and home hemodialysis are good alternatives for treatment. Currently available telemedicine and medical technologies allow for effective renal replacement therapy also outside dialysis centers. Thanks to this, it is possible to limit the stay of patients in a medical facility to clinically justified situations. For this reason, increasing the number of patients treated with peritoneal dialysis, which is carried out at home and without contact with medical personnel, seems to be a good solution. Enabling patients to undergo home hemodialysis treatment, nowadays unavailable in Poland and establishing it as a guaranteed benefit in the health care system will enable renal replacement therapy to be adapted to the clinical condition and the need for isolation.
\end{abstract}

KEY WORDS: dialysis, COVID19, home hemodialysis, outbreak

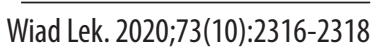

In the first twenty years of the $21^{\text {st }}$ century, three species of viruses from the Coronaviridae family (SARS-CoV, MERS-CoV and SARS-CoV-2) caused serious local or global threats of acute respiratory failure. SARS-CoV-2 is probably the most infectious virus in this family, although the course of the infection appears to be milder. Compared to the two previous SARS-CoV and MERS-CoV epidemics, the current SARS-CoV-2 epidemic is much broader and covers the entire world. According to the WHO data, 37.109.851 cases of infection have been confirmed on all continents so far, and 1.070.355 people have died as a result of infection with the virus. [1] The city of Wuhan has been identified as the source and center of the pandemic, with over 50,000 confirmed cases and 3,869 deaths by April $26,2020 .[2]$

In the view of the current epidemiological situation, it seems that dialysis patients require special management due to medical factors such as numerous comorbidities (diabetes, hypertension, heart failure) and immunity disorders, but also due to the need for treatment in dialysis centers. This is related to regular, several-hour stay in the room with other patients and medical staff, as well as ambulance journeys, which unfortunately increases the risk of spreading the virus. $[3,4,5]$ All these factors increase the risk of infection and serious complications of COVID-19 among patients treated with renal replacement therapy, which is a new challenge for healthcare professionals, patients and healthcare managers. The scientific world has responded extremely quickly to the pandemic. Thousands of publications on SARS-CoV-2 infection appeared in the weeks following the publication of the WHO's preliminary report on January 5, 2020 on the new virus epidemic in Hubei Provence. [6] Despite or in connection with such a large number of publications, it is very difficult to find information that could be relevant to clinical practice and that could help in better organization of medical care for dialysis patient. [7]

Previous SARS-CoV and MERS-CoV epidemics mainly affected East Asian and Middle East countries. Some of them, such as Hong Kong, Korea or Saudi Arabia, have developed algorithms and guidelines in the event of similar situation in the future. Now these documents provide valuable resources for others who are creating guidelines for the prevention and management of SARS-CoV-2 infection. $[8,9,10,11]$ The authors of these guidelines indicate strict compliance with hygiene recommendations (disinfection, use of personal protective equipment by medical personnel and patients) and the need to keep a safe distance between patients during dialysis and transport (1.2 to $2 \mathrm{~m}$ between patients) as the main elements of preventing the spread of infection. Increasing the distance between patients and isolating those infected reduces the risk of virus transmission and reduces the number of infections among dialysis patients. However, isolation poses a serious risk of stigmatizing infected patients and can even trigger post-traumatic stress disorder because of isolation or infec- 
tion itself. [12] In addition, the need to stay several times a week in facility where the risk of infection may be higher may create additional psychological burden for patients. Additional growing threat are numerous infections among medical staff (physicians, nurses) which cause the shortage of personnel in dialysis centers and finally influence on quality of in-center treatment. In some selected cases healthcare providers, according to the National Consultant consent have decided to provide the dialysis treatment without a physician supervision. Also sometimes dialysis centers changed their schedules (mainly by deacreasing HD session time) to deliver the treatment in situation of medical staff shortage.

Currently available ICT (telemedicine) and medical technologies allow for effective renal replacement therapy also outside dialysis centers. Thanks to this, it is possible to limit the stay of patients in a medical facility to clinically justified situations. For this reason, increasing the number of patients treated with peritoneal dialysis, which is carried out at home and without contact with medical personnel, seems to be a good solution. Currently, in Poland, less than $5 \%$ of patients requiring renal replacement therapy are treated by peritoneal dialysis. The spread of peritoneal dialysis therapy would reduce the risk of COVID-19, which could theoretically occur during treatment at a dialysis station. It seems that in any patient with end-stage renal disease starting renal replacement therapy, treatment with peritoneal dialysis treatment should be considered first.

Chinese researchers, based on the observation of patients treated with peritoneal dialysis at home and hemodialysis in a dialysis station, concluded that severe PTSD symptoms appear more often in the group of patients treated with hemodialysis. [13] Home hemodialysis is another effective method to reduce the time spent in the dialysis station. So far, this method is not available in Poland, although it seems that it could be an alternative for patients with contraindications to peritoneal dialysis treatment. Over the past few years, there has been development of home hemodialysis in the United States and some Western European countries, which may now accelerate due to the pandemic. [14] This trend was already evident during the 2014 Ebola virus epidemic, when home hemodialysis was considered as a treatment for patients with end-stage renal disease and Ebola infection. [15]

Both of the above-mentioned methods of renal replacement therapy (peritoneal dialysis and home hemodialysis) in combination with available IT solutions that enable contact with medical staff in real time allow for effective and safe renal replacement therapy, reducing the risk of contact and possible transmission of pathogens. It is obvious that these methods have some limitations - the patient ability (mental and physical) to provide self treatment or possibility of assistance from the family members, the possibility to install the medical equipment at home and space for storing the disposables. The crucial factor for successful implementation of home dialysis are proper selection of the patients and training performed correctly. As home hemodialysis is well developed in Western Europe countries
(Netherlands, France) and USA, the training programs as well as technical issues are already solved and could be almost one-to-one implemented in Poland. For sure home hemodialysis and peritoneal dialysis remains the methods for selected patients (10-20\% of patients receiving RRTs) but both of them should be available in the country and implemented much wider than today.

Enabling patients to undergo home hemodialysis treatment and establishing it as a guaranteed benefit in the health care system will enable renal replacement therapy to be adapted to the clinical condition and the need for isolation.

\section{REFERENCES}

1. COVID 19 WHO report; www.https://covid19.who.int/. Date accessed 120 ctober 2020.

2. National Health Commission of The Peoples Republic of China, COVID-19 epidemic situation report. 2020. http://en.nhc.gov.cn/202004/27/c_79657.htm. Date accessed 28 th August 2020.

3. Ikizler TA, Kliger SA. Minimazing the risk of COVID-19 among patients on dialysis. Nat Rev Nephrol 2020; doi: https://doi.org/10.1038/s41581020-0280-y.

4. Li J, Xu G. Lessons from the Experience in Wuhan to Reduce Risk of COVID-19 Infection in Patients Undergoing Long-Term Hemodialysis. CJASN 2020;15. doi: https://doi.org/102215/CJN.03420320

5. Kliger SA, Silberzweig J. Mitigating Risk of Covid-19 in Dialysis Facilities. CJASN; 2020;15; doi: https://doi.org/10.2215/CJN.03340320

6. World Health Organization. Pneumonia of unknown cause - China. https://www.who.int/csr/don/05-january-2020-pneumonia-ofunkown-cause-china/en/. Date accessed 28 th August 2020.

7. Ikizler TA. COVID-19 and Dialysis Units: What Do We Know Now and What Should We Do. https://www.ajkd.org/action/ showPdf?pii=S0272-6386\%2820\%2930608-9. Date accessed 28 th August 2020.

8. Hayne CP, Young-Ki L, Sang-Ho L, et al, and The Korean Society of Nephrology MERS-CoV Task Force Team. Middle East respiratory syndrome clinical practice guideline for hemodialysis facilities. Kidney Res Clin Pract. 2017 Jun;36(2):111-116.

9. Oh MD, ParkWB, Park SW et al. Middle East respiratory syndrome: what we learned from the 2015 outbreak in the Republic of Korea. Korean J Intern Med 2018;33(2):233-246

10. Saudi Arabia Ministry of Health. Middle East Respiratory Syndrom Coronavirus; Guideline for Healthcare Professionals. https://www. moh.gov.sa/CCC/healthp/ regulations/Documents/MERS-CoV\%20 Guidelines $\% 20$ for $\% 20$ Healthcare\% 20Professionals\%20-2 20 May\%20 2018\%20-\%20v5.1\%20\%281\%29.pdf. Date accessed 28 th August 2020.

11. Park HC, Lee SH, Kim J, et al. Effect of isolation practice on the transmission of middle east respiratory syndrome coronavirus among hemodialysis patients. A 2-year prospective cohort study. Medicine 2020;99(3): e18782.

12. Cho AJ, Lee $H$, Lee $Y$, et al. Post-traumatic stress symptoms in hemodialysis patients with MERS-CoV exposure. BioPsychoSocial Med 2020;14(9) https://doi.org/10.1186/s13030-020-00181-z

13. Xiaoxiao X, Xiaofang W, Xueli Z, Zhiyun Z, Li P, Zi L. Comparison of psychological distress and demand induced by COVID-19 during the lockdown period in patients undergoing peritoenal dialysis and hemodialysis: a cross-section study in a tertiary hospital. MedRxiv preprint. doi: https://doi.org/10.1101/2020.04.13.20063099 
14. Charnow JA. COVID-19 Crisis Could Speed Adoption of Home Dialysis. www.renalandurologynews.com/home/news/nephrology/ hemodialysis/covid-19-crisis-could-speed-adoption-of-home-dialysis. Date accessed 25 April 2020.

15. Boyce JM, Hymes JL. What we Learned from Ebola: Preparing Dialysis Unit for the Next Outbreak. Clin J Am Soc Nephrol. 2018 Apr 6;13(4):669-670

\section{ORCID and contributionship}

Paweł Żebrowski - 0000-0003-2826-0253 A, D-F

Jacek Zawierucha - 0000-0001-7980-4842 A, B, D, F

Wojciech Marcinkowski - 0000-0002-2172-1822 E-F

Tomasz Prystacki - 0000-0002-6564-8217 ${ }^{\text {E-F }}$

Inga Chomicka - 0000-0001-7472-2266 ${ }^{\mathrm{E}-\mathrm{F}}$

Jolanta Malyszko - 0000-0001-8701-8171 A, E-F

\section{Conflict of interest}

Authors declare no conflict of interest

\section{CORRESPONDING AUTHOR}

Jolanta Malyszko

Nephrology, Dialysis and Internal Medicine, Warsaw Medical University Banacha 1 a, 02-097, Warszawa, Poland

tel.: 48225992658

e-mail:jolmal@poczta.onet.pl

Received: 05.09 .2020

Accepted: 15.10 .2020

A - Work concept and design, B - Data collection and analysis, C - Responsibility for statistical analysis,

D-Writing the article, $\mathbf{E}$-Critical review, $\mathbf{F}$ - Final approval of the article 